\title{
Fractional cover mapping of spruce and pine at 1 ha resolution combining very high and medium spatial resolution satellite imagery
}

\author{
Markus Immitzer ${ }^{\mathrm{a}, *}$, Sebastian Böck ${ }^{\mathrm{a}}$, Kathrin Einzmann ${ }^{\mathrm{a}}$, Francesco Vuolo ${ }^{\mathrm{a}}$, Nicole Pinnel ${ }^{\mathrm{b}}$, \\ Adelheid Wallner ${ }^{\mathrm{c}}$, Clement Atzberger ${ }^{\mathrm{a}}$

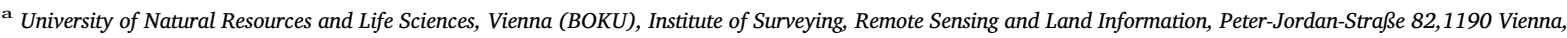 \\ Austria \\ ${ }^{\mathrm{b}}$ German Aerospace Center (DLR), German Remote Sensing Data Center (DFD), Department of Land Surface, Münchner Straße 20, 82234 Weßling, Germany \\ c Bavarian State Institute of Forestry (LWF), Department of Information Technology, Research Group: Remote Sensing, Hans-Carl-von-Carlowitz-Platz 1, 85354 Freising, \\ Germany
}

\section{A R T I C L E I N F O}

\section{Keywords:}

Upscaling

Random Forest regression

WorldView-2

Landsat

Fractional cover

Tree species mapping

\begin{abstract}
A B S T R A C T
Increases in extreme weather events associated with climate change have the potential to put currently healthy forests at risk. One option to minimize this risk is the application of forest management measures aimed at generating species mixtures predicted to be more resilient to these threats. In order to apply such measures appropriately, forest managers need up-to-date, accurate and consistent forest maps at relatively fine spatial resolutions. Cost efficiency is a major factor when creating such maps. Taking European spruce (Picea abies) and Scots pine (Pinus sylvestris) as an example, this paper describes an innovative approach for mapping two tree species using a combination of commercial very high resolution WorldView-2 (WV2) images and Landsat time series data. As a first step, this study used a supervised object-based classification of WV2 images covering relatively small test sites distributed across the region of interest. Using these classification maps as training data, wall-to-wall mapping of fractional coverages of spruce and pine was achieved using multi-temporal Landsat data and Random Forests (RF) regression. The method was applied for the entire state of Bavaria (Germany), which comprises a total forested area of approximately $26,000 \mathrm{~km}^{2}$. As applied here, this two-step approach yields consistent and accurate maps of fractional tree cover estimates with a spatial resolution of 1 ha. Independent validation of the fractional cover estimates using 3780 reference samples collected through visual interpretation of orthophotos produced root-mean-square errors (RMSE) of 11\% (for spruce) and 14\% (for pine) with almost no bias, and $\mathrm{R}^{2}$ values of 0.74 and 0.79 for spruce and pine, respectively. The majority of the validation samples (75\% (spruce) and $84 \%$ (pine)) were modeled within the assumed uncertainty of $\pm 15 \%$ of the reference sample. Accuracies were significantly better compared to those achieved using a single-step classification of Landsat time series data at the pixel level $(30 \mathrm{~m})$, because the two-step approach better captures regional variation in the spectral signatures of target classes. Moreover, the increased number of available reference cells mitigates the impact of occasional errors in the reference data set. This two-step approach has great potential for cost-effective operational mapping of dominant forest types over large areas.
\end{abstract}

\section{Introduction}

Climate change is expected to have an important influence on future growing conditions that will likely have a great impact on tree species. Depending on the location, some trees species will benefit, for example, from increasing temperatures and thus, extended vegetation periods. However, at other locations, increased temperatures are likely to lead to water stress, and hence, greater vulnerability of some tree species to abiotic and biotic disturbances (Lindner et al., 2010). In Central Europe, several coniferous tree species are of particular concern: the vulnerability of tree species such as European spruce and Scots pine is particularly high in areas where they are planted outside their natural ranges (Kölling et al., 2009a; Lindner et al., 2014; Seidl et al., 2017). As both species are of high economic importance for the European forest sector, targeted forest management is necessary to minimize economic losses. In order to identify areas of increased risk, Kölling et al. (2009b) produced risk maps for different tree species based on different climate scenarios for Bavaria, Germany. Identification of particularly

\footnotetext{
* Corresponding author.

E-mail address: markus.immitzer@boku.ac.at (M. Immitzer).
} 
vulnerable forest stands at a fine spatial resolution is a logical follow-up step to ensure efficient planning of silvicultural activities. Therefore, risk maps depicting (future) growing conditions must be combined with precise species distribution information. Unfortunately, data of sufficient detail for tree species distribution at a suitable spatial resolution (i.e. percentage cover in 1 ha cells) is still missing.

Long-established forest inventories in Europe provide important data about forest composition based on precise information obtained from field plots where repeated periodic terrestrial observations are made. However, the data collected is inappropriate for providing detailed enough spatial information at the local to regional levels to guide forest management decisions of the scale required to meet the challenges brought about by climate change. In order to extrapolate information obtained from these spatially specific plots to a wider area, spatial interpolation methods such as kriging have been employed in the past. Such procedures permit production of distribution maps of tree species based on inventory data. The European Forest Institute (EFI), for example, has produced Europe-wide maps using data mainly obtained from national forest inventories (Brus et al., 2012). These data provide a good overview of the general distribution of the species, but at $1 \mathrm{~km}$ spatial resolution, these maps still lack sufficient spatial detail, particularly for less abundant species. The tree species distribution maps available from the Forest Information System for Europe (JRC, 2017) are another example of a data set with similar limitations.

Earth Observation (EO) derived data products covering large areas usually only provide information on the presence or absence of forests or on percent tree cover. Prominent examples of such products are the global forest cover and forest cover change maps based on moderate resolution imaging spectroradiometer (MODIS) and/or Landsat data sets (Hansen et al., 2013; Kim et al., 2014; Sexton et al., 2013; Townshend et al., 2012). Other products covering Europe only separate major tree species groups such as coniferous and broadleaf trees. Examples of these classifications include the forest high resolution layer (EEA, 2017a), the Pan-European forest type map (JRC, 2015) and the coordinated information on the environment (CORINE) land cover inventory (EEA, 2017b). An overview and comparison of various land cover products derived from EO data can be found in Pérez-Hoyos et al. (2012).

Studies analyzing species distribution at a more detailed level, e.g. with up to ten different species and often at the level of individual trees, are mainly based on optical EO data with high to very high spatial resolutions (VHR), such as IKONOS or WorldView-2 (WV2) (Carleer and Wolff, 2004; Fassnacht et al., 2017; Immitzer et al., 2012; Kim et al., 2011; Mora et al., 2010; Waser et al., 2014). Hence, the high potential of VHR data when applied within specific pilot studies and for relatively small areas has been confirmed. Detailed studies and examples that cover larger geographic extents, however, are still missing (Fassnacht et al., 2016).

The use of VHR data is often limited by high data costs. Consequently, most applications that cover large areas have focused on the use of cloud-free mosaics based on freely available data from the Landsat family which are often produced using the Best-Available-Pixel (BAP) method (Griffiths et al., 2013; Hermosilla et al., 2015; White et al., 2014; Zhu et al., 2015). With the launch of the European Sentinel2 satellites, data with higher spatial, spectral and temporal resolutions have become available, creating new opportunities for tree species separation at the stand level (Immitzer et al., 2016b).

A recent overview of the possibilities, advantages and limitations of different satellite sensor data and methods can be found in a review from Fassnacht et al. (2016). The authors found that (i) the selected approaches and/or data sets often do not permit application to larger areas, (ii) most existing studies cover only small areas (in particular those based on VHR data), and (iii) data from passive sensors in the optical domain have greater potential for tree species separation than those from active sensors. This last finding is particularly true in terms of tree species whose phenological characteristics change significantly with changes in season, making acquisition and processing of multitemporal imagery important. Gómez et al. (2016) concluded that depending on the temporal resolution of the data used, both inter-annual changes and intra-annual dynamics (e.g. phenological development) can be detected using data from multiple time points. Recent examples of using multi-temporal Landsat data for classification include a land cover map of Germany provided by Mack et al. (2017) and the tree species and basal area maps of northern New York and Vermont produced by Gudex-Cross et al. (2017).

To improve land cover maps, some research groups have investigated the possibility of combining satellite data with different spatial resolutions. Well-known examples in forestry are studies that have combined data sets from Landsat and AVHRR (Fries et al., 1998) or Landsat and MODIS (Hansen et al., 2000). Other studies have derived continuous variables such as percent forest cover by combining Landsat and AVHRR (Iverson et al., 1989; Zhu and Evans, 1994). More recent studies have combined Landsat data with data sets of higher spatial resolutions such as IKONOS (Metzler and Sader, 2005) or GeoEye-1 data (Donmez et al., 2015). While most studies of this kind have focused on one general forest class, Metzler and Sader (2005) estimated the percentage cover of softwoods and hardwoods separately.

Techniques such as multiple regression (Iverson et al., 1989; Metzler and Sader, 2005; Zhu and Evans, 1994) or decision tree-based approaches (Donmez et al., 2015; Hansen et al., 2000; Thompson et al., 2015) can be used to create images of continuous variables, such as percentage of a given tree species. In recent years, the Random Forest algorithm has become popular for modeling continuous forest attributes based on EO data (Immitzer et al., 2016b; Mutanga et al., 2012; Stepper et al., 2017; Thompson et al., 2015; White et al., 2015). The key advantages of this non-parametric technique are that it requires relatively few assumptions about the structure of the data set, delivers information about the importance of the individual input data, provides an internal bootstrapping method for independent validation and utilizes a relatively fast and robust modeling framework.

Combining VHR data with freely available Landsat-type data has the potential for providing coverage of a larger spatial area along with the advantages of the detailed information data of high spectral resolution provides. To the best of our knowledge, no studies have yet been published that combine satellite data sets with very high $(<5 \mathrm{~m})$ and medium $(30 \mathrm{~m})$ spatial resolutions for continuous (fractional) mapping of individual tree species. This study presents such an approach for estimating the fractional coverage of spruce and pine in 1 ha cells for the entire German state of Bavaria. This is realized with a two-step approach including: (i) classification of several VHR WV2 scenes distributed over the study area and covering only a part of the region of interest; and (ii) modeling the spruce and pine fractional cover derived from these VHR maps using spectral and temporal metrics derived from Landsat as explanatory variables. Finally, application of the calibrated models to the total area covered by the Landsat data yields maps covering the entire federal state of Bavaria.

The main objectives of the research presented here were to:

- Examine the suitability of Landsat time series data for upscaling tree species information derived from VHR imagery.

- Evaluate the added value of the two-step approach compared to a standard pixel-based classification of Landsat data.

- Quantify the trade-offs between the number of VHR scenes used (data acquisition and processing costs) and the quality of the maps generated.

For comparison, a pixel-based classification of Landsat time series data using the same reference data was applied. Both products were validated using an independent data set collected through visual interpretation of orthophotos. 


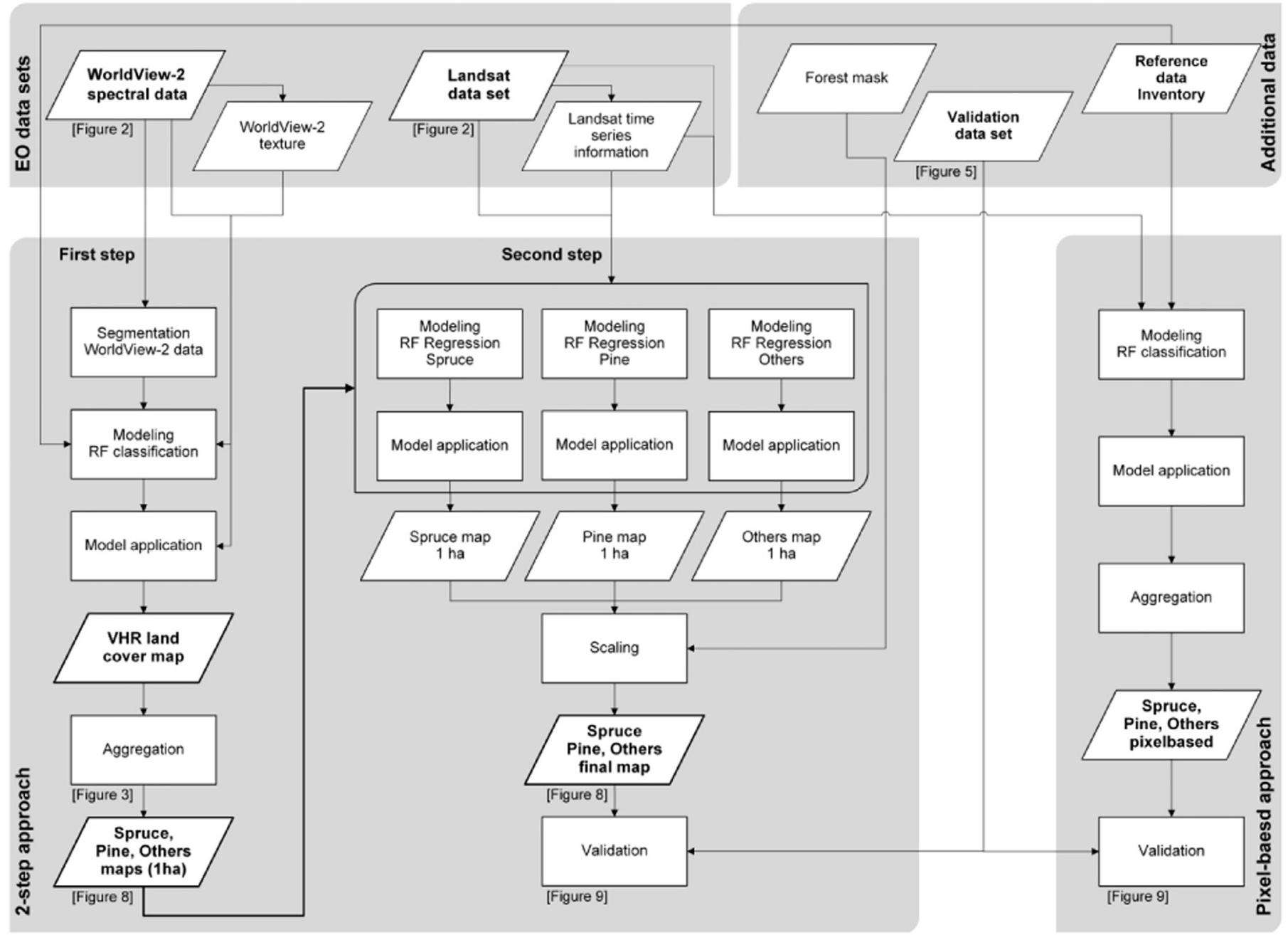

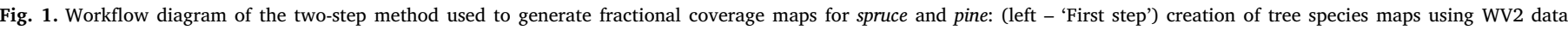

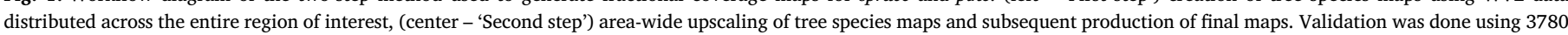

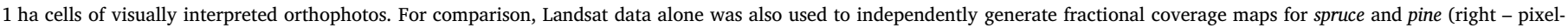
based approach).

\section{Methods}

To produce fractional coverage maps of spruce and pine for the entire state of Bavaria, a two-step approach was developed (Fig. 1). First, VHR 'reference' land cover maps were produced at $2 \mathrm{~m}$ spatial resolution using a supervised object-based approach performed on $47 \mathrm{WV} 2$ scenes. The WV2 scenes were distributed across Bavaria, and cover roughly $20 \%$ of the total land area in the state. In a second step, the VHR land cover maps were used as reference information to upscale to the entire federal state of Bavaria. This was done using RF modeling to create classes for spruce (primarily European spruce, Picea abies (L.) H. Karst.), pine (primarily Scots pine, Pinus sylvestris L.) and others (all other tree species and non-forest land cover classes). The aggregated VHR tree species maps combined with data obtained from a cloud-free Landsat time series mosaic were used as reference data to create explanatory variables for use in a subsequent modeling step. To remove data gaps due to clouds and cloud shadows, smoothed and gap-filled Landsat time series data (Vuolo et al., 2017) were used. This also avoids the need for separate modeling of data derived from each Landsat acquisition path.

To assess the accuracy of the two-step approach, the three fractional coverages generated by the model were subsequently verified and validated using 37801 ha cells of visually interpreted orthophoto samples. We also assessed the impact of using fewer WV2 scenes on the accuracy of the models generated. In addition, a 'classical' (pixel-based) classification of Landsat data was performed to compare the proposed approach against a simpler procedure.

The statistical software R 3.0.1 (R Core Team, 2014) and the packages caret (Kuhn et al., 2014), matrixStats (Bengtsson, 2014), raster (Hijmans, 2014) and randomForest (Liaw and Wiener, 2002) were used for the modeling step.

\subsection{Study site - the federal state of Bavaria, Germany}

With an area of approximately $70,500 \mathrm{~km}^{2}$, Bavaria is the largest federal state in Germany. Around 37\% of the land area is covered with forests. Growing conditions are quite diverse in Bavaria, with oceanic influences in the north-west, a (sub)boreal climate in the north-east and subalpine conditions in the south. The largest part of Bavaria is characterized by a subcontinental or intermediate climate. The dominant life zones are colline to submontane, with some montane areas in the east and the south. As a consequence, the potential natural forest community would be dominated by different Fagetum types accompanied by some Quercetum types in the north-east and Piceetum types in the east and south (Walentowski et al., 2001). The actual forests have an average timber volume of $400 \mathrm{~m}^{3} /$ ha and are dominated by Norway spruce $(41.8 \%)$, and Scots pine (17.1\%) interspersed with largely naturally established stands of European beech (13.9\%) (Klemmt et al., 2014). Due to climate change, many spruce and pine forests are highly 

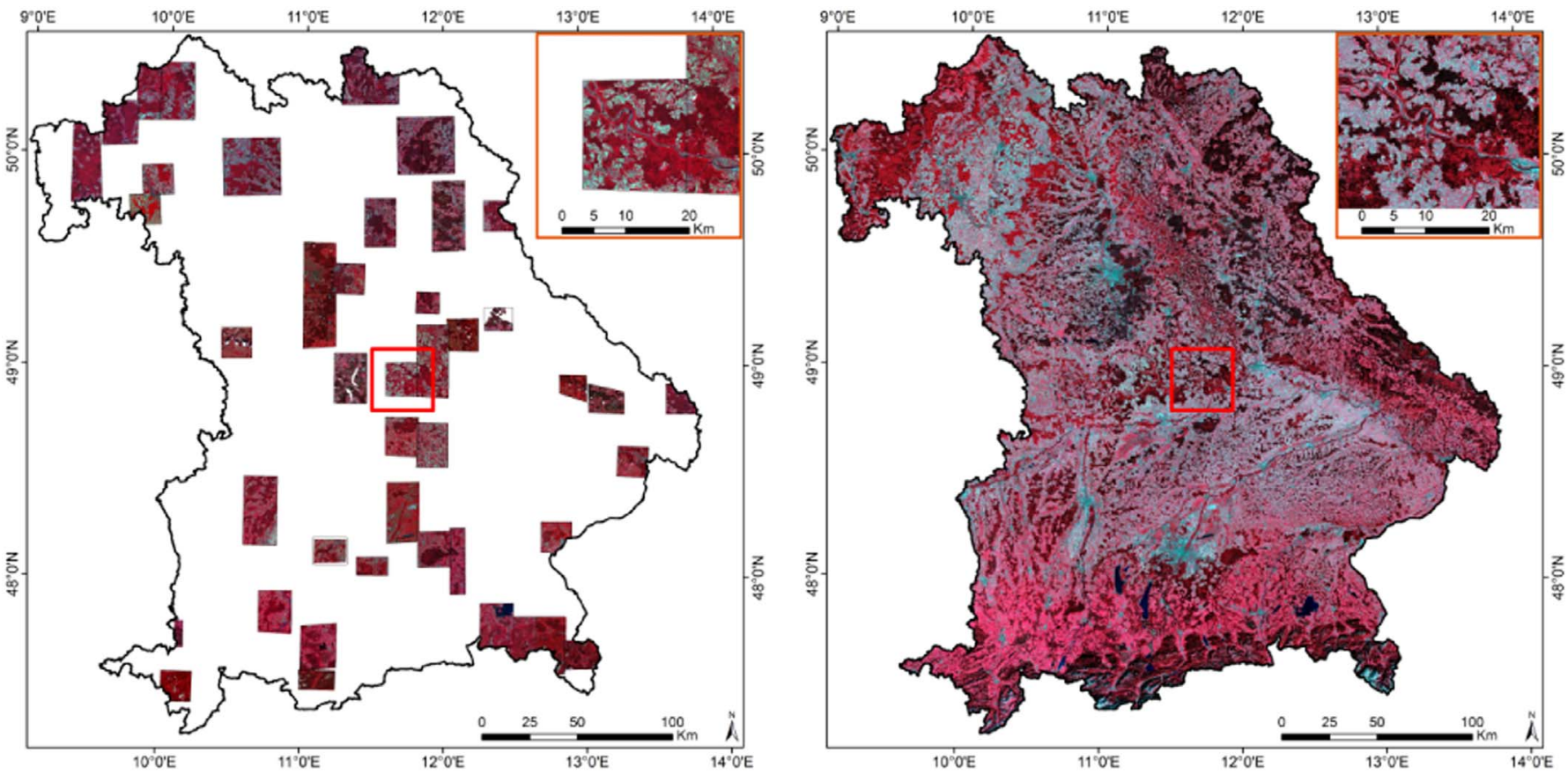

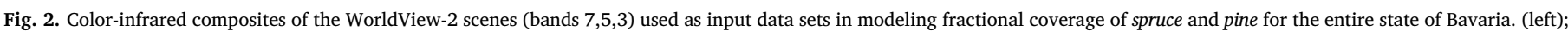
Example of a gap-filled and smoothed Landsat data mosaic (bands: 4,3,2) for August 2013 (right).

stressed, leading to increasing biotic and abiotic risks, in particular in areas where these species are planted outside their natural ranges (Kölling et al., 2009a; StMELF, 2013). Therefore, forest management activities are necessary to generate better-adapted stands with a mixture of tree species that is more resilient to changing climate conditions (Kölling et al., 2009a).

\subsection{Data sets}

\subsubsection{WorldView-2 data}

Forty-seven WV2 scenes ( $2 \mathrm{~m}$ pixel size) were used in this analysis. Scene selection was done to ensure representation of the forest ecoregions of Bavaria (Walentowski et al., 2001) and the availability of forest inventory data from the Bavarian state forest enterprise (BaySF) for these areas. To limit data costs, archived data were selected when possible, and new acquisitions of scenes were only requested when no usable archive data was available. The distribution of the WV2 scenes used is shown in Fig. 2, and detailed information about the scenes is found in Table S1 (Supplementary materials).

All WV2 data were pre-processed at the German Aerospace Center (DLR) using the automatic processing chain CATENA (Krauß et al., 2013; Reinartz, 2010), which includes orthorectification (Müller et al., 2005) and atmospheric \& topographic correction (ATCOR) (Richter et al., 2006).

\subsubsection{Landsat time series data}

To model the fractional coverage of spruce and pine, a smoothed and gap-filled Landsat (LS) time series data set of images acquired in 2013 was used. Details about the process by which this data set was produced can be found in Vuolo et al. (2017). The approach yields a data set of bimonthly cloud-free Bottom of Atmosphere (BoA) reflectance in the six Landsat spectral bands. An illustration of a data set for the second half of August 2013 is shown in Fig. 2. An example showing both raw and processed data can be found in Vuolo (2016).

Compared to the original Landsat scenes, the main advantage of smoothed and gap-filled Landsat time series data are:

(i) A higher number of cloud-free observations per year (24 observations per pixel and year), equally distributed over the entire time period, and hence, covering all seasons.

(ii) Spatially homogenous data over a large spatial extent.

In addition to the reflectance values in six spectral channels, several metrics derived from normalized difference vegetation index (NDVI, (Rouse et al., 1974)) images produced from the time series data were included in the analyses. These include:

- two NDVI values for each month (bi-monthly data),

- mean annual NDVI value,

- difference between average summer and winter NDVI values (amplitude).

\subsection{Classification of WorldView-2 data and generation of reference fractional coverage information}

An object-based approach using both spectral and textural information was used to classify each individual WV2 scene. Depending on the image location, landscape and species mixture represented in the reference data, up to 12 different land cover classes per scene were created (Fig. 3).

For image segmentation, eCognition Developer 8 was used. The parameters were fine-tuned for each scene to ensure that homogenous forest stands or tree groups were obtained and to avoid segmentation of individual tree crowns. Reference information based on inventory data as well as on visual interpretation of orthophotos and stereo aerial images was manually assigned to the segments.

For each segment, statistical values (mean, standard deviation, percentiles) for each of the eight spectral bands of the WV2 data and additional texture layers were produced (Table 1). The texture layers were derived from the red and near infrared bands and the NDVI image using a discrete stationary wavelet transformation (coiflets-family: coif1) similar to that used by Einzmann et al. (2017). More details about the wavelet transformation can be found in Toscani et al. (2013) and Immitzer et al. (2014).

The reference data sampling focused on the two target classes spruce and pine, with additional classes representing other forest and non- 


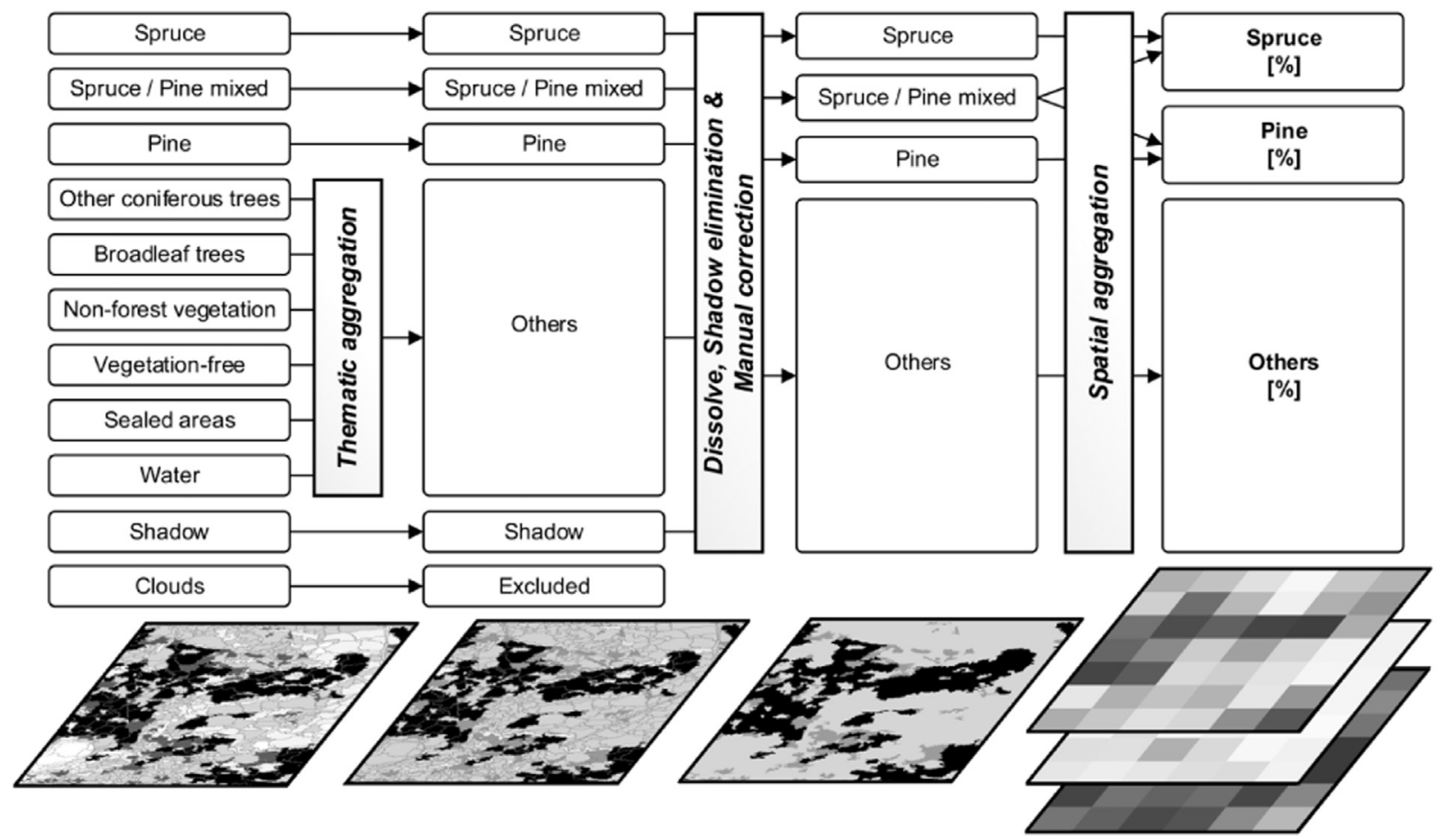

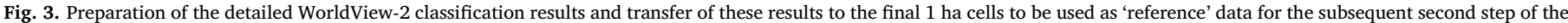
approach. The workflow includes thematic aggregation, shadow elimination and spatial aggregation.

forest classes where present. In regions with mixed stands of spruce and pine, a mixed class was also assigned. The reference data set creation was based on forest inventory data and color infrared (CIR) orthophoto interpretation. Approximately 850 training samples were generated for each scene.

This reference data was then used to perform a supervised classification using Breiman's (2001) Random Forest (RF) algorithm. The parameter mtry was set to the square root of available input variables (default) and the ntree parameter to 1000. Detailed information about this ensemble learning algorithm and its advantages, such as the integrated bootstrapping that provides relatively unbiased 'out-of-bag' (OOB) results, can be found in the literature (Breiman, 2001; Hastie et al., 2009; Immitzer et al., 2012; Pal, 2005).

To optimize the classification output, a recursive feature selection process (Guyon et al., 2002) using the importance information obtained from RF was applied. The classification procedure with feature selection is described in detail in Immitzer et al. (2015) and Schultz et al. (2015).

After classification, both thematic and a spatial aggregation were carried out (Fig. 3). First, all classes except spruce, pine, mixed spruce and pine, shadow and clouds were combined to create one class labeled others. Neighboring polygons of the same classes were then dissolved, and 'shadow' polygons were merged with the neighboring polygon with which they shared the longest border. The classification results obtained were visually compared to orthophotos, and corrected when necessary to prevent classification errors from propagating to the final modeling product. Non-interpretable areas and the clouds class were set to 'no data' (NA) and excluded from the procedures that followed. For the subsequent spatial aggregation, a Bavaria-wide raster with a pixel size of 1 ha was produced, and, in the areas covered by the WV2 scenes, fractional coverages (in \%) for each of three classes pine, spruce, and others were calculated for each 1 ha cell. The mixed spruce and pine class was allocated equally to the two main classes. Cells including NA areas and those not fully covered by the WV2 classification results were discarded.

\subsection{Upscaling of the classification results to area-wide maps}

After creation of the reference data set, the second part of the method involved developing models for mapping fractional coverages of spruce and pine for the entire forested area of Bavaria. For the Landsat data sets, all pixels were disaggregated to $10 \mathrm{~m}$ spatial resolution using a nearest neighbor resampling algorithm aligned to the 1 ha grid of cells from the fractional coverage map. The aligned $10 \mathrm{~m}$ pixels were then summarized in terms of mean, standard deviation and percentiles to characterize the distribution of reflectance values and the NDVI values within each 1 ha cell (Table 2).

$\mathrm{RF}$ regression models were then trained for each of the three classes spruce, pine and others using the aggregated information described in the previous section. Explanatory variables were obtained from available Landsat time series data, including both spectral reflectance values and NDVI. From those variables, additional features such as amplitude and

Table 1

Explanatory variables for the classification models used in the first step of the approach.

\begin{tabular}{|c|c|c|c|}
\hline EO input data & No. of layers & Metrics calculated for each polygon & No. of explanatory variables \\
\hline WorldView-2 spectral bands & 8 & $\begin{array}{l}\text { Mean, standard deviation, percentiles: minimum, 5th, 10th, 25th, median, 75th, } \\
\text { 90th, 95th, maximum }\end{array}$ & 88 \\
\hline $\begin{array}{l}\text { Normalized difference vegetation index } \\
\quad \text { (NDVI) }\end{array}$ & 1 & $\begin{array}{l}\text { Mean, standard deviation, percentiles: minimum, 5th, 10th, 25th, median, 75th, } \\
\text { 90th, 95th, maximum }\end{array}$ & 11 \\
\hline Wavelet coiflet1 texture & 12 & $\begin{array}{l}\text { Mean, standard deviation, percentiles: minimum, 5th, 10th, 25th, Median, 75th, } \\
\text { 90th, 95th, maximum }\end{array}$ & 132 \\
\hline
\end{tabular}


Table 2

Explanatory variables for the regression models created in the second step of the approach.

\begin{tabular}{|c|c|c|c|}
\hline EO input data & No. of layers & Metrics calculated for each 1 ha cell & No. of explanatory variables \\
\hline Landsat Reflectance June 2013 & 6 & $\begin{array}{l}\text { Mean, standard deviation, percentiles: minimum, 25th, median, } \\
\text { 75th, maximum }\end{array}$ & 42 \\
\hline Landsat Reflectance Aug 2013 & 6 & $\begin{array}{l}\text { Mean, standard deviation, percentiles: minimum, 25th, median, } \\
\text { 75th, maximum }\end{array}$ & 42 \\
\hline $\begin{array}{l}\text { Normalized difference vegetation index (NDVI) bi-monthly time } \\
\text { series } 2013\end{array}$ & 24 & Mean, standard deviation & 48 \\
\hline $\begin{array}{l}\text { Normalized difference vegetation index (NDVI) bi-monthly time } \\
\quad \text { series } 2013\end{array}$ & 24 & Amplitude and mean value March to August, mean of the year & 3 \\
\hline
\end{tabular}

mean values of the vegetation period were extracted. For the reflectance values, only data sets from the end of June 2013 and the end of August 2013 were used. A comprehensive list of all explanatory variables is provided in Table 2 . RF regression models were used, as they have a number of advantages that are particularly relevant for this application. These advantages include a reduced risk of overfitting the model, determination of variable importance, and the ability to handle different data types (Gómez et al., 2016; Hastie et al., 2009; Immitzer et al., 2016a). Similar to the classification approach, the RF regression includes internal bootstrapping, and provides relatively unbiased 'outof-bag' (OOB) results.

Within each WV2 classification result converted to class-specific proportions, 50001 ha cells were extracted as training samples. Training points were chosen such that all cells having the highest proportion (top 2\%) of the classes spruce and pine were sampled, with the remaining points chosen randomly. RF models were generated separately for each of the three target classes spruce, pine, and others. First, an RF model was built using all available Landsat metrics. Based on the feature importance information obtained from the RF model, the 100 most important explanatory variables were chosen to build a new model. The default values for ntree (500 trees) and mtry (third of the total number of input features) were used in model creation. Next, the models for each of the three classes were separately applied to the entire study area. Afterwards, the three maps were combined and, if necessary, rescaled so that the classes summed to $100 \%$ for each 1 ha cell. Areas outside of forests were manually set to $100 \%$ others using the vectorized forest information (forest mask) from the Authoritative topographic-Cartographic Information System (ATKIS) (AdV, 2015).

\subsection{Reduction of the number of WorldView-2 scenes}

The use of a large number of VHR scenes entails high costs for data provision and analysis. To better understand the cost-benefit relationship between accuracy and number of WV2 scenes used, the input scenes were reduced iteratively from the original 47 (total number of available WV2 scenes) to 1, using a greedy algorithm. In each step, the WV2 scene which led to the smallest increase in the average distance of empty cells to the sampled training cells of the respective nearest scene was removed.

Greedy algorithms have the advantage of being fast and easy to compute but do not necessarily lead to optimal solutions. Also, content and data quality of the individual WV2 scenes are not considered in this approach, which is depicted in Fig. 4.

\subsection{Comparison to pixel-based classification of Landsat data}

To demonstrate and quantify the added value of the two-step approach, a standard pixel-based classification of the LS data set was performed for comparison. Again in this case, an RF classification (ntree $=1000, m$ try $=$ square root of the number of input features) was done using the same reference data which were used to classify the WV2 scenes, excluding the mixed spruce and pine class. For each reference polygon, the most central $(30 \mathrm{~m})$ LS pixel was used. Eight classes were distinguished: spruce, pine, other coniferous trees, broadleaf trees, non-forest vegetation, water, natural areas without vegetation and sealed areas. In total, the number of reference pixels used for the classification was 4870 for spruce, 2080 for pine, 2821 for other coniferous trees, 5805 for broadleaf trees and 8031 for non-forest vegetation, 3190 for water, 2369 for natural areas without vegetation and 8251 for sealed areas. The same 37 Landsat metrics used in the upscaling done in the two-step approach (Table 2) were used for the pixel-based RF classification. The model was applied to the entire study site. Again, all classes except spruce and pine were combined to create a class labeled others. The pixel-based classification results were subsequently aggregated to the 1 ha cells in the same way described above, to create a second set of fractional coverages for each of the three classes.

\subsection{Validation using independent samples from orthophotos}

For independent validation, a regular raster grid of the entire state of Bavaria with $2.5 \mathrm{~km} \times 2.5 \mathrm{~km}$ cell size was produced. For each of the 3780 raster points inside the forest mask, the corresponding 1 ha cell was assigned a class based on visual interpretation of CIR orthophotos conducted by experienced photo-interpreters. The fractional coverages of the three classes spruce, pine and others were assessed in 5\% steps. The resulting independent validation data set is shown in Fig. 5.

To assess the relative precision and accuracy of the two models (i.e. the two-step approach vs. the pixel-based Landsat classification), the root mean squared error (RMSE), the bias and the coefficient of determination $\left(\mathrm{R}^{2}\right)$ were calculated for each class (spruce, pine, others) independently (see, for example Immitzer et al., 2016a for formulas).

\section{Results}

\subsection{Land cover maps based on WV2 scenes}

The median OOB overall accuracy (OA) for the 47 WV2 scenes was 93.8\% (ranging from 87.6 to $97.4 \%$ ), with some variation in classspecific results (Fig. 6). Note that classes which were only present in some WV2 scenes were aggregated to more general class groups. For example, European larch, Douglas fir and white fir were combined in Fig. 6 to create the class other coniferous tree species (post-classification grouping).

The producer's accuracies (PA) for spruce ranged between 76.1 and 98.4\% (median 88.0\%), and those for pine between 30.4 and $100 \%$ (median 85.9\%). The user's accuracy (UA) ranged between 70.6 and 95.9\% (median $\mathbf{8 8 . 2 \%}$ ) for spruce and 58.3 and 100\% (median $84.7 \%$ ) for pine. The values for the other forest classes showed similar variation. The non-forest classes achieved higher accuracies with lower variability amongst the 47 WV2 scenes (Fig. 6).

As expected, image quality (acquisition date and acquisition parameters) determined the usability of the WV2 data for tree species separation. Data from scenes acquired in summer months (June to August) and acquisitions with near-nadir view angles showed the highest suitability and achieved the highest accuracies (Supplementary materials Table S1). For good class-specific performance, an adequate 

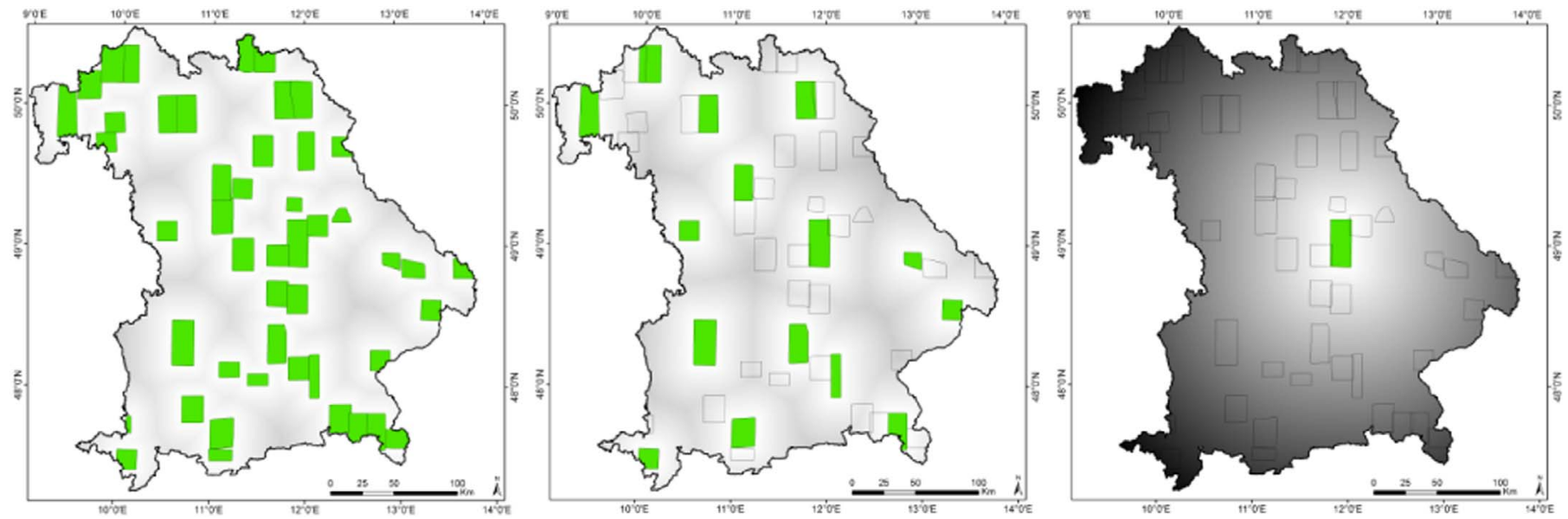

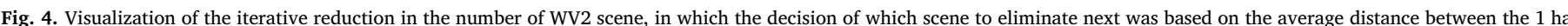

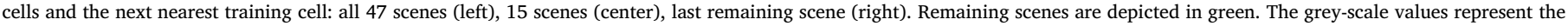

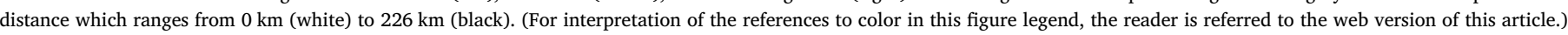

number of high-quality reference data was necessary.

The confusion matrix based on the $\mathrm{OOB}$ results of all reference data is shown in Table 3. To generate this confusion matrix, the results of the 47 individual WV2 scenes were again combined. The class mixed spruce and pine had the lowest class-specific accuracy, as this class was mainly confused with the (pure) spruce and pine classes. Next to the mixed class, the two other forest classes coniferous tree species and broadleaf tree species showed the highest confusion with the two target classes spruce and pine.

A visual check of the classified images sometimes revealed differences in model performance and map accuracy. Apparent misclassifications of the main classes spruce and pine were manually corrected to avoid negative impacts on the final maps. The average resulting change in the classification was around $2.5 \%$ of the classified area (roughly one working day per scene). For some scenes, a greater amount of effort was necessary, as scene quality and/or reference data were sub-optimal (Supplementary materials Table S1).

For the second step, 5000 samples (1 ha cells) from each spatially and thematically aggregated WV2 classification result were used. The data distribution for each of the three classes is shown in Fig. 7.

\subsection{Bavarian-wide spruce and pine maps}

The RF regression models based on all 47 WV2 scenes, using only the most important Landsat-based predictor variables, explained $79.8 \%$ of the variance for spruce, $77.0 \%$ for pine and $87.9 \%$ for the class others

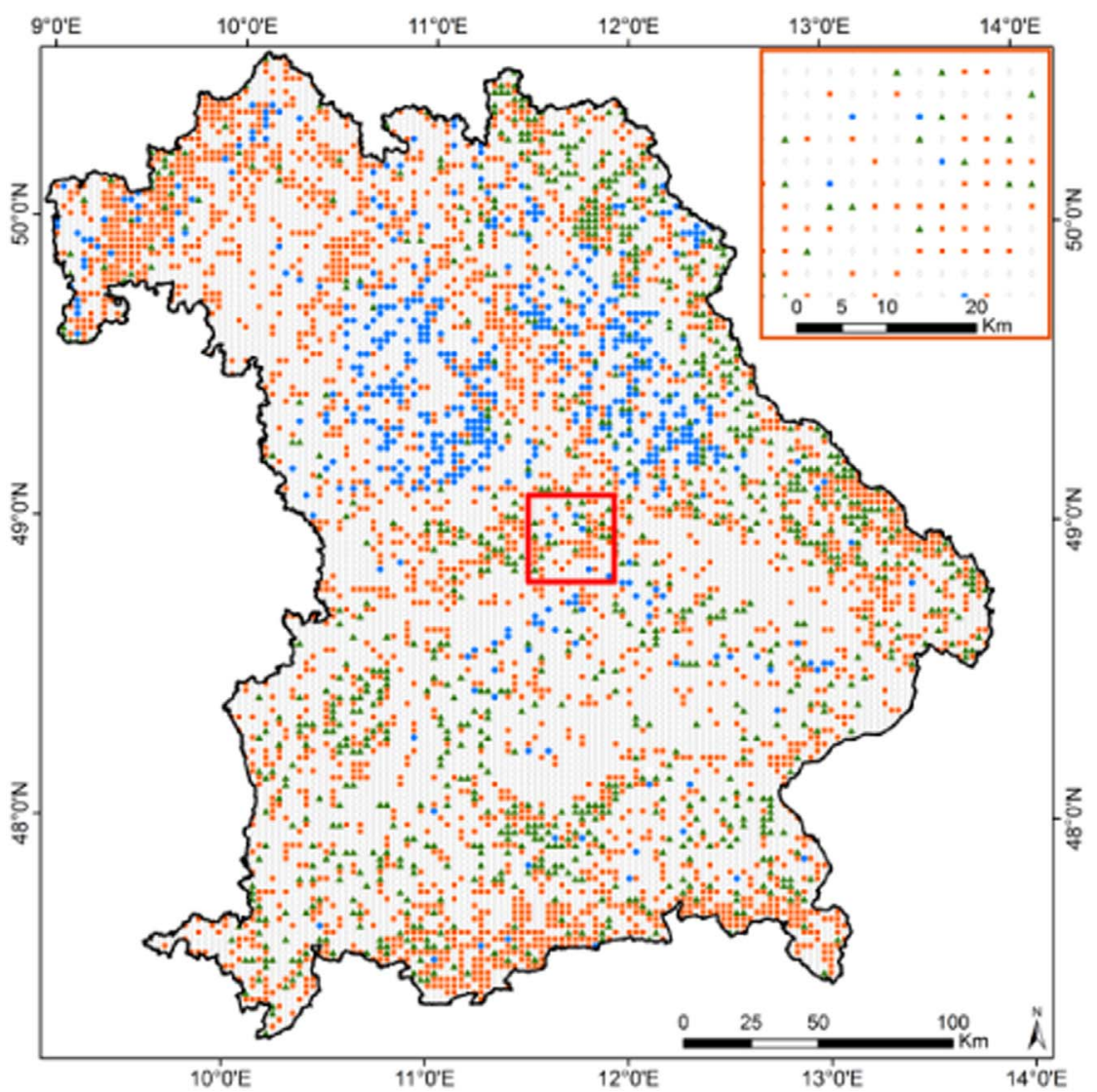

Fig. 5. Independent validation data set (regular $2.5 \mathrm{~km} \times 2.5 \mathrm{~km}$ raster) produced by visual interpretation of the corresponding 1 ha cell using orthophotos. The colors represent the dominant class: green triangles indicate spruce, blue circles represent pine, red squares illustrate others and grey diamonds, non-forest (only areas inside the forest mask were interpreted). (For interpretation of the references to color in this figure legend, the reader is referred to the web version of this article.) 


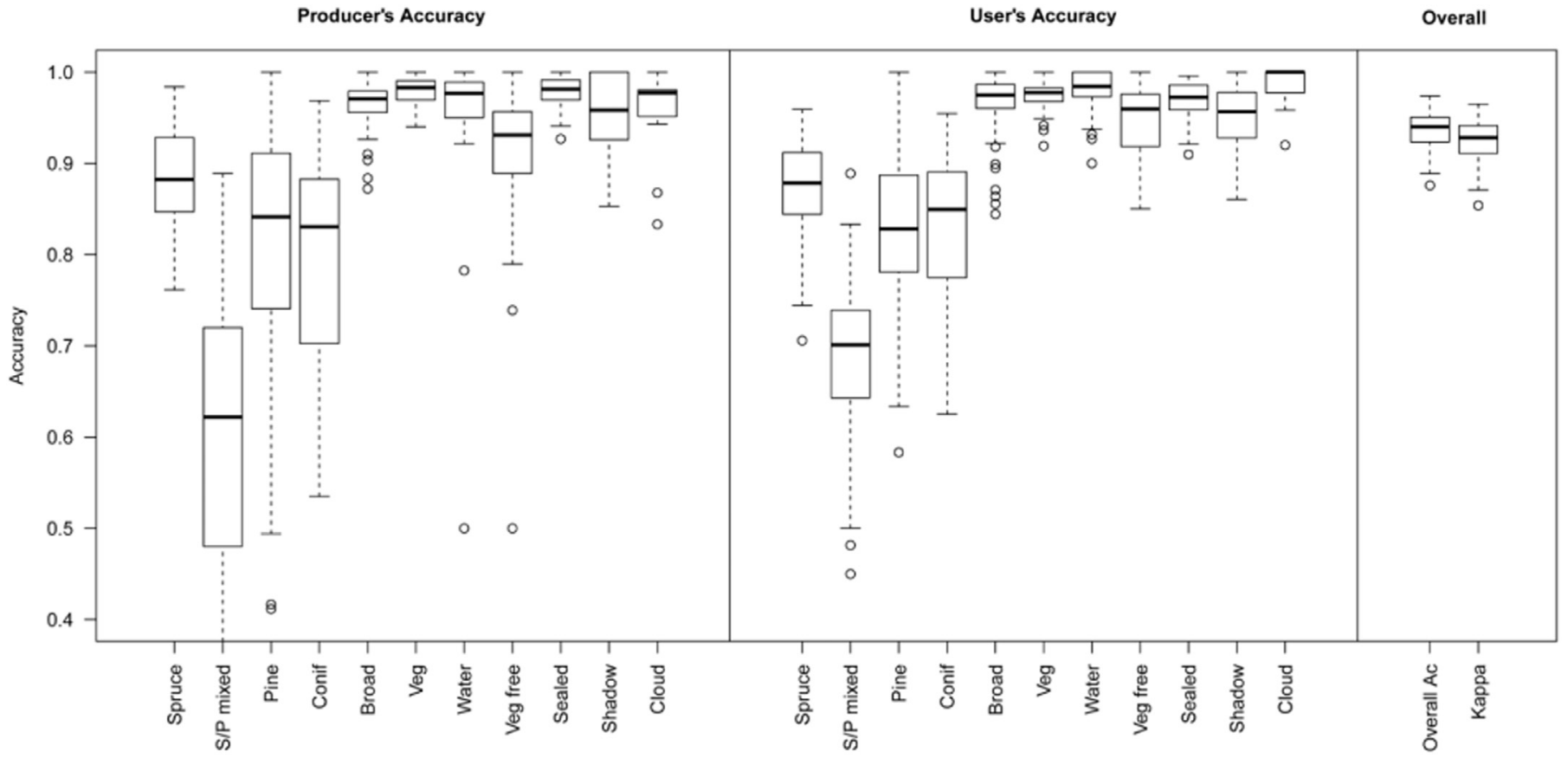

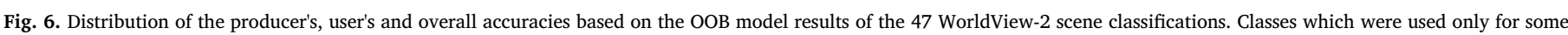

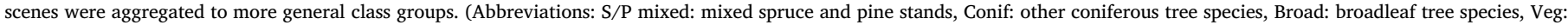
non forest vegetation, Veg free: natural areas without vegetation).

(OOB results). The most important variables for the spruce modeling were the spectral reflectance values from the two Landsat data sets (Bands 1, 4 and 3) and NDVI values from all seasons. Similar features were important for the pine models, with the main difference being increased importance of the NDVI metrics.

The results of the two-step mapping are presented in Fig. 8. The maps show fractional coverages of spruce and pine from the WV2 classifications (top) and the Landsat-based upscaling (bottom), at a spatial resolution of 1 ha. For $>90 \%$ of the 1 ha cells the sum of the fractional coverage results of the three classes ranged between 98 and 102\%. For the final maps, all cells were rescaled to yield $100 \%$ in total.

The results of the independent validation of the two-step approach and the direct (pixel-based) classification of Landsat data are shown in Fig. 9. The $\mathrm{R}^{2}$ values for spruce and pine were 0.72 and 0.75 , respectively. The RMSE was $12.1 \%$ for pine and $14.2 \%$ for spruce. For all three classes, bias was close to zero. With an $\mathrm{R}^{2}$ value of 0.82 , the highest correlation with the two-step approach was found for the class others, which in this case represents only the other forest classes, as the validation was applied only in forested areas.

The results for the pixel-based classification of the LS data (OOB results are given in the Supplementary materials Table S2) were considerably worse (Fig. 9, center row). For all three classes, significantly lower $\mathrm{R}^{2}$ values, higher RMSE and higher bias values were observed. The bottom row of Fig. 9 illustrates the model deviations from the independent validation data. For example, in the case of the two-step approach for spruce, approximately $75 \%$ of the 1 ha cells are modeled within the error margin of $\pm 15 \%$, while only $67 \%$ of the cells were correctly modeled using the pixel-based approach. The bar charts in Fig. 10 further summarize the strong improvement $\left(\mathrm{R}^{2}\right.$, RMSE and bias) obtained with the two-step mapping approach.

\subsection{Reduction of WV2 scenes}

To test the influence of the number of inputs, the number of WV2 scenes used was reduced in a step-wise process. With a decreasing number of scenes, the $\mathrm{R}^{2}$ decreased and the RMSE increased (Fig. 11).

Table 3

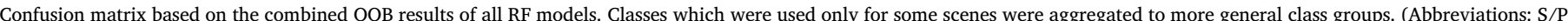

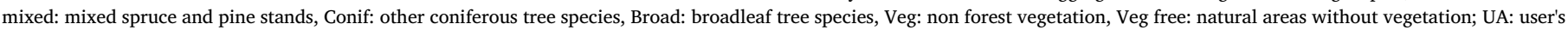
accuracy, PA: producer's accuracy, OA: overall accuracy).

\begin{tabular}{|c|c|c|c|c|c|c|c|c|c|c|c|c|c|}
\hline & Spruce & $\mathrm{S} / \mathrm{P}$ mixed & Pine & Conif & Broad & Veg & Water & Veg free & Sealed & Shadow & Clouds & $\Sigma$ & UA \\
\hline Spruce & 4319 & 141 & 117 & 333 & 46 & 11 & 1 & 1 & - & 21 & - & 4990 & 0.866 \\
\hline $\mathrm{S} / \mathrm{P}$ mixed & 108 & 501 & 98 & 11 & - & 4 & 1 & - & - & 2 & - & 725 & 0.691 \\
\hline Pine & 105 & 128 & 1699 & 94 & 18 & 7 & 1 & 2 & - & 10 & - & 2064 & 0.823 \\
\hline Conif & 238 & 9 & 98 & 2237 & 68 & 7 & 1 & 2 & - & 18 & 1 & 2679 & 0.835 \\
\hline Broad & 51 & - & 38 & 100 & 5574 & 50 & 1 & 1 & - & 17 & 2 & 5834 & 0.955 \\
\hline Veg & 15 & - & 15 & 28 & 70 & 7860 & 3 & 22 & 60 & 1 & 10 & 8084 & 0.972 \\
\hline Water & - & - & - & - & - & - & 3103 & 2 & 27 & 31 & 1 & 3164 & 0.981 \\
\hline Veg free & - & - & 1 & 1 & - & 21 & 2 & 2201 & 66 & - & 18 & 2310 & 0.953 \\
\hline Sealed & - & - & - & - & 1 & 68 & 53 & 119 & 8087 & 11 & 2 & 8341 & 0.970 \\
\hline Shadow & 34 & 4 & 13 & 17 & 28 & 3 & 24 & - & 6 & 2285 & - & 2414 & 0.947 \\
\hline Clouds & - & - & 1 & - & - & - & - & 19 & 5 & - & 1660 & 1685 & 0.985 \\
\hline$\Sigma$ & 4870 & 783 & 2080 & 2821 & 5805 & 8031 & 3190 & 2369 & 8251 & 2396 & 1694 & 42,290 & \\
\hline \multirow[t]{2}{*}{ PA } & 0.887 & 0.640 & 0.817 & 0.793 & 0.960 & 0.979 & 0.973 & 0.929 & 0.980 & 0.954 & 0.980 & $\mathrm{OA}$ & 0.935 \\
\hline & & & & & & & & & & & & Карра & 0.925 \\
\hline
\end{tabular}



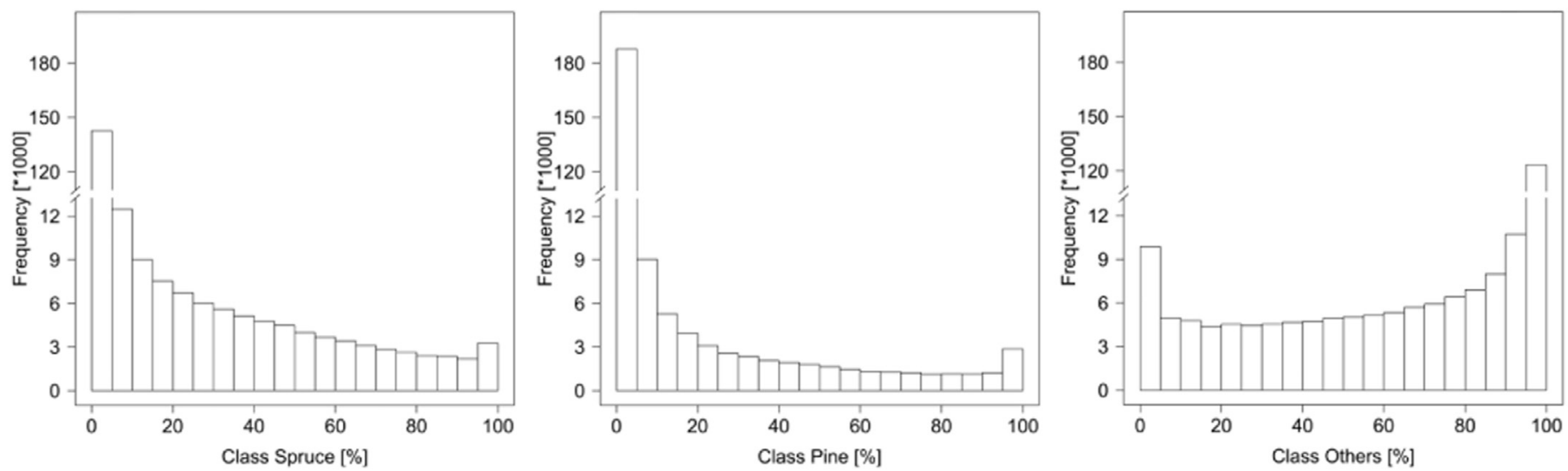

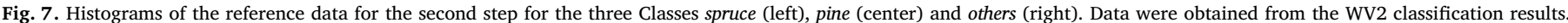

However, the modeling accuracy decreased only slightly when the number of scenes used was reduced from the original 47 to 15 WV2 scenes. Only below this point did further reduction of the number of WV2 scenes lead to significant decreases in model performance. A relatively close relationship is seen between the modeling error (e.g. RMSE) and the average distance of (empty) cells to the location of the nearest WV2 scene (bottom of graphs), demonstrating the strong impact of (spatially) well distributed and dense training samples (here coverage with very high resolution data) on modeling accuracy.

\section{Discussion}

\subsection{Model approach}

Compared to a conceptually and computationally simpler pixelbased classification, our two-step method achieved considerable improvement in accuracy using the same basic reference data. The likely source of the increase in model accuracy is the fact that the two-step process allowed substantially more training points to be collected than is possible using a simple pixel-based classification. By first classifying WV2 data; we obtained a larger amount of reference data, likely better capturing the spectral differences between the mapped tree species. Peculiarities in spectral and temporal signatures may, for example, result from differences in stand management and/or growing conditions at a particular site. In addition, the large amount of reference data can reduce the influence of possible misclassification introduced in the first step.

The presented two-step method for mapping fractional coverage of tree species gave good results, with $75 \%$ (spruce) to $84 \%$ (pine) of the validation samples being modeled within the assumed uncertainty of $\pm 15 \%$ of the reference samples. The achieved $R^{2}$ values based on the independent validation samples were only slightly lower than the OOB results for the three RF regression models, with similar trends and patterns. This confirms the validity of $\mathrm{OOB}$ statistics for assessing RF models mentioned in other studies (Hastie et al., 2009; Immitzer et al., 2016a).

A completely independent validation based on orthophoto interpretation using a regular grid covering the entire study site was performed to assess model accuracies. The disadvantage of this approach is that spatial shifts (or layover effects) between the orthophotos and the map products could potentially have negative impacts on validation accuracy. Nevertheless, we obtained satisfactory results. Our study achieved $\mathrm{R}^{2}$ values for the three target classes ranging from 0.72 to 0.82 that are notably higher than those found in a similar study by Metzler and Sader (2005). They reported $\mathrm{R}^{2}$ values of around 0.66 for the two classes when upscaling soft- and hardwood coverages obtained from IKONOS data to (multi-temporal) Landsat data. However, their analysis was carried out in a different geographic area with different target variables, thus limiting the value of a direct comparison. Other studies using similar approaches for modeling forest cover also obtained similar $\mathrm{R}^{2}$ values of around 0.80 (Donmez et al., 2015; Iverson et al., 1989; Sexton et al., 2013).

The mapped spatial distribution of spruce and pine is similar to those produced by the European Forest Institute (EFI) (not shown) based on kriging of inventory data (Brus et al., 2012). However, the maps produced in our study have two main advantages: (i) they provide a higher spatial resolution, and (ii) the artifacts which sometimes appear in the EFI maps for species with rare(r) occurrences (e.g. strong overestimation around single inventory plots) are absent.

Compared to the official figures for spruce and pine acreages provided by the Bavarian State Institute of Forestry, we found distinct differences. According to the official data derived from National Forest Inventory (NFI) plots, spruce covers $41.8 \%$ of the forested area of Bavaria, and pine $17.1 \%$ (Klemmt et al., 2014). From our data, however, we calculated only $30.1 \%$ for spruce and $14.9 \%$ for pine. We believe that the differences mainly result from diverging definitions of 'coverage'. For example, in our approach, we map the percentage crown coverage in each 1 ha cell, whereas in the NFI a forest gap is counted as spruce if it is located inside a spruce stand.

\subsection{Considerations regarding the VHR input data}

The classification of the WV2 data achieved very good results overall. This is in line with several other studies that have demonstrated the great potential of WV2 data for detailed land cover mapping, including forest (Fassnacht et al., 2017; Immitzer et al., 2012; Karlson et al., 2016; Omer et al., 2015; Waser et al., 2014).

The main drawback of WV2 data is its relatively high cost. Depending on the number of occurring tree species in a given study area, less expensive data with fewer spectral bands (see, for example Waser et al., 2011 for use of airborne imagery) could possibly be equally suitable for tree species classification (Immitzer et al., 2012). As discussed, the sole purpose of the use of WV2 data in our study was to expand the amount of detailed data available for training of RF regression models. This could potentially also be achieved by making use of other pre-existing high resolution maps. Fassnacht et al. (2016) for example highlighted the fact that most of the tree species classification studies considered in their review paper were data-driven and covered only very small test sites with limited operational implementation opportunity. Hence, maps resulting from such small-scale studies could be interesting input data sets for use in upscaling approaches such as the method presented here. Using pre-existing classification results (even those from different sensors) could further reduce data costs and, therefore, be a cost-efficient tool for producing large-scale tree species maps. Obviously, the quality of the VHR tree species classification is very important for the overall modeling approach. Any 

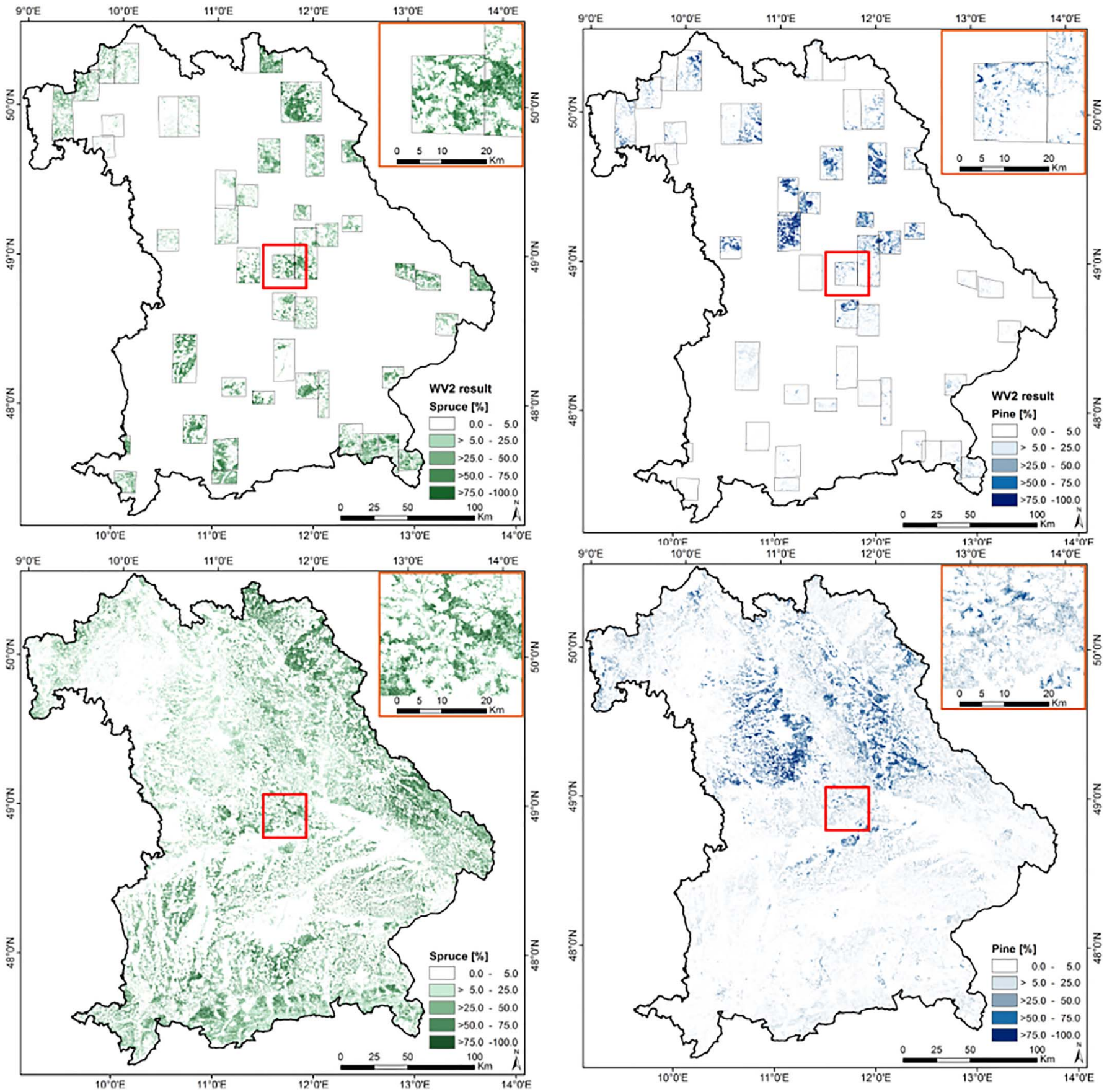

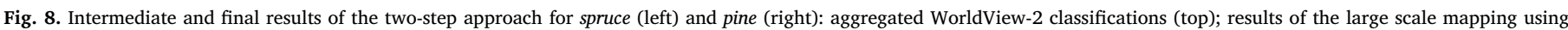
Landsat time series to scale the WorldView-2 classifications up to the entire state of Bavaria (bottom).

misclassification will negatively influence model accuracy in the second step.

As expected, the date of the image collection and the acquisition parameters had significant impacts on the resulting classification accuracy. We used $47 \mathrm{WV} 2$ scenes with off-nadir angles ranging from 2 to $25^{\circ}$. These images were acquired between the end of April and the end of September. The scenes acquired in April or the beginning of May were sub-optimal for tree species differentiation, due to the leafless state of deciduous trees. In scenes covering mountainous areas, even images from late May were not always adequate, since the broadleaf trees in the valley had already developed leaves, whereas in the leaves were still absent at higher elevations. For tree species classification in Central Europe, we suggest using images acquired between mid-June and the end of August. This proposed acquisition period also minimizes the potential for negative impacts from illumination effects, like the length of cast shadows.

Another important factor influencing the quality of the classifications was variation in off-nadir angle and viewing geometry. The images used in this analysis were acquired with different off-nadir angles. The scenes with angles up to $15^{\circ}$ were generally satisfactory. However, with higher view angles, especially those $>20^{\circ}$, we observed some noticeable distortions in the images. This effect was most pronounced in scenes with hilly terrain.

In order to assess the impact of the number of input scenes versus mapping accuracy, we analyzed a higher number of WV2 scenes than was thought necessary for an optimal cost versus accuracy trade-off. By experimenting with using fewer scenes, we demonstrated that a far smaller number of scenes are sufficient if these scenes are well 

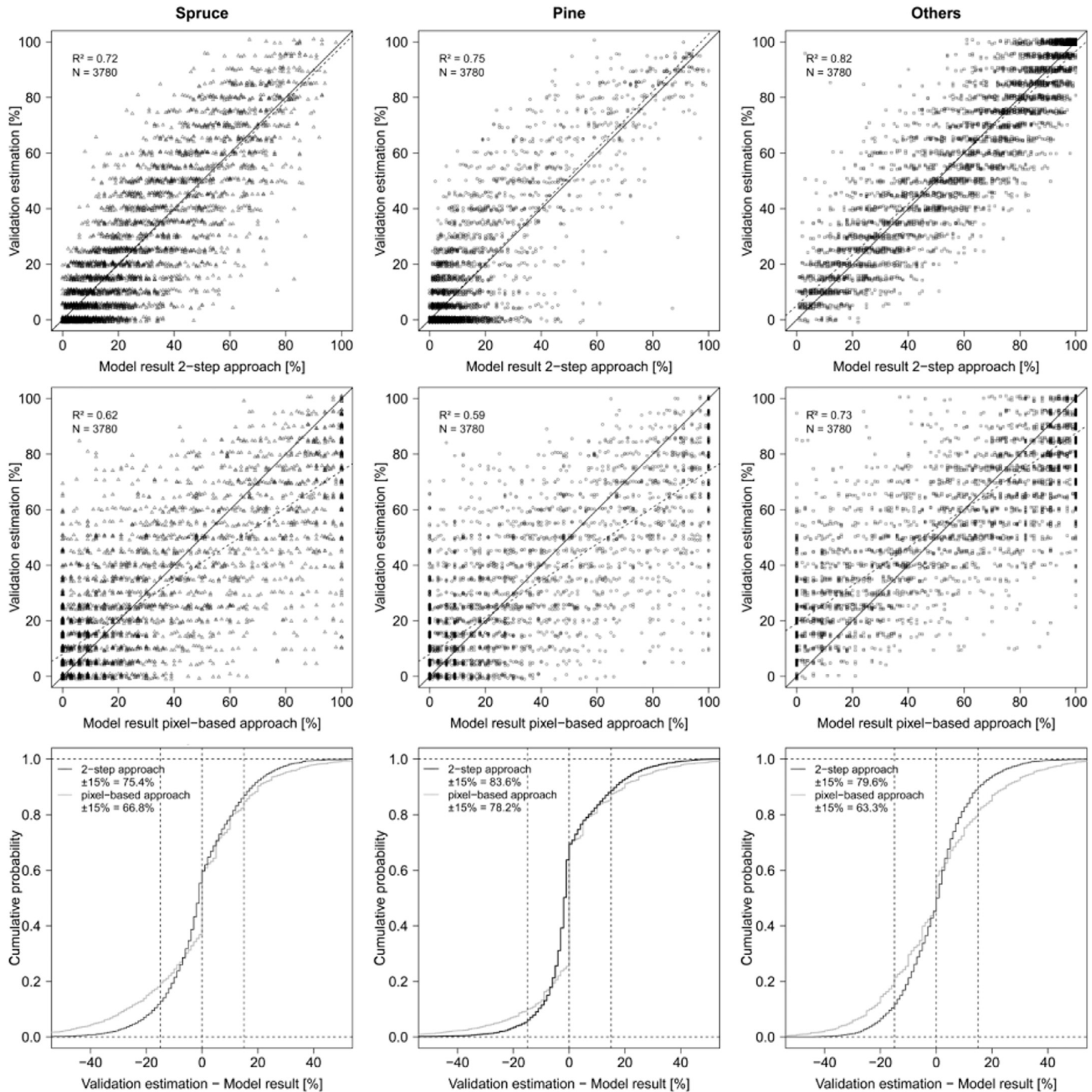

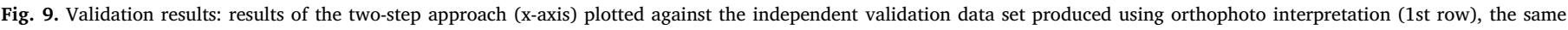

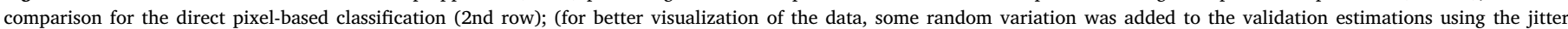

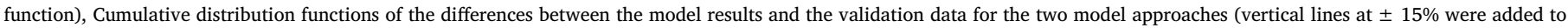
display the probable uncertainty margin of the visual reference estimation) (3rd row).

distributed over the study area and cover the various land cover and forest types present in the study area. In this particular case, we observed nearly no decrease in model performance as the number of WV2 scenes used as inputs was reduced from 47 to 15 . Only below that number, did errors begin to increase significantly, likely because critical training samples were no longer available. The training data obtained from these 15 scenes covers roughly $1 \%$ of Bavaria, as only 5000 cells from each scene were used for the modeling approach (covering a total land area of $750 \mathrm{~km}^{2}$ ).

\subsection{Suitability of Landsat time series data to generate explanatory variables}

Ten Landsat scenes from four paths (192 to 195) are necessary to cover the entire land area of Bavaria. Getting cloud-free data for such a large area (acquired within a short time interval and close to key phenological dates) is a challenge. Difficulties increase if multi-temporal data are necessary to be able to distinguish between spectrally similar classes (Beck et al., 2006; Ju and Roy, 2008). To minimize the impacts of clouds and acquisition time, we first tried to identify and process suitable data for two dates from each path. Modeling was done 

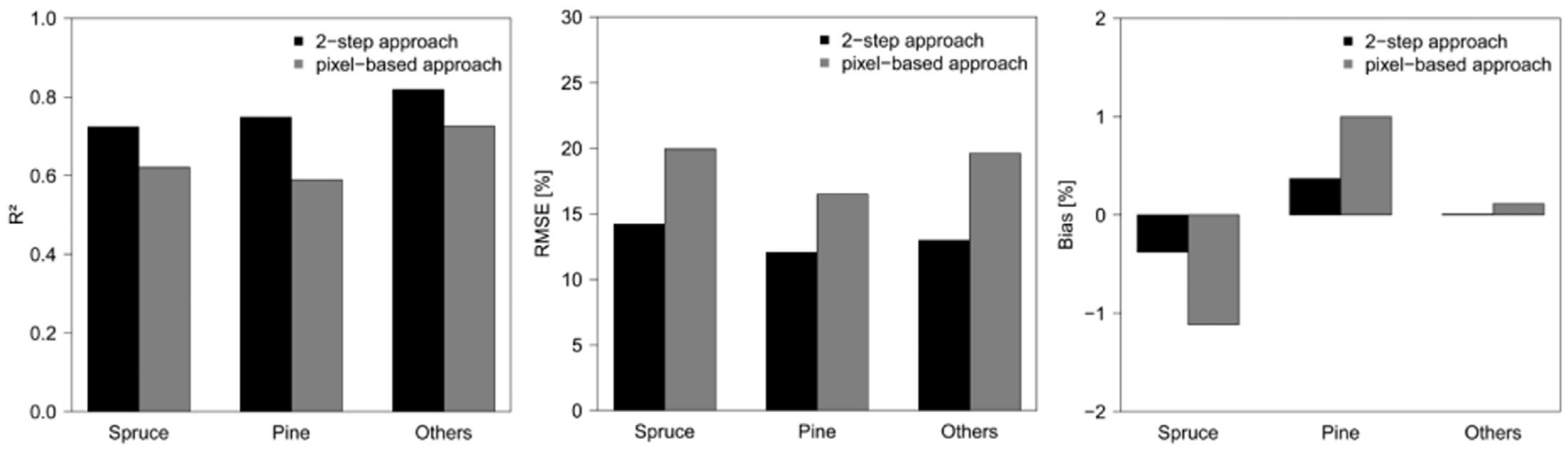

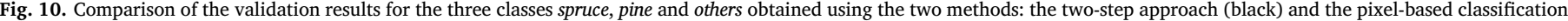
(grey): $\mathrm{R}^{2}$ values (left), RMSE values (center), and bias values(right).

for each path separately (Immitzer et al., 2015). This requires the availability of a sufficient amount of WV2 data per path. After modeling, some post-processing is required to mosaic the mapping results from the four paths together to create area-wide maps. To avoid problems related to the strip-wise data processing, we used in this study gap-filled time series data (Vuolo et al., 2017). The gap-filling process involves the creation of wall-to-wall homogeneous mosaics in the original Landsat spectral bands at bi-monthly temporal resolution (Fig. 2). Hence, the entire study region can be processed in one step. For the three classes spruce, pine and others we obtained nearly identical performance: $\mathrm{R}^{2}$ values for spruce, pine and others were $0.72,0.75$ and 0.82 , compared to $0.74,0.79$ and 0.83 when processing the data strip-bystrip (Immitzer et al., 2015). Similar results were found for the RMSE, while the bias was reduced by using the gap-filled data.

Using smoothed and gap-filled Landsat data (Vuolo et al., 2017) thus, simplifies processing and offers a number of further advantages: (i) any number of cloud-free images from one specific vegetation period can be used, and (ii) fewer reference data are necessary, as larger areas are covered than in the original Landsat scenes/paths. Both aspects deserve more research. In particular, we did not utilize the full time series of spectral data, but instead used data from only two time steps (Table 2). Using additional data could be useful, especially in efforts to map a larger number of tree species.

\section{Conclusion}

The two-step method developed in this research provides a good framework for producing high quality tree species maps for large areas. The generated mapping results are important for forest monitoring and management activities. Specifically, the spruce and pine maps generated in this study will be combined with risk maps by the Bavarian State Institute of Forestry to be used in locating hot spots where forest conversion activities should be prioritized. The fractional coverage maps at a resolution of 1 ha are potentially useful for several other applications such as landscape modeling or monitoring tasks.

The method developed here combines large-area Landsat mosaics with very high resolution (VHR) WorldView-2 (WV2) data covering only a relatively small part of the region of interest in a computationally efficient way. The use of WV2 data permits expansion of the reference data later available to train the RF models based on Landsat metrics. The use of Landsat data for the final mapping considerably reduces the costs associated with the acquisition and processing of commercial VHR data over large areas.

In the present study, the approach was solely applied to map spruce and pine. Obviously, application to other species is possible. The method also permits the use of pre-existing (high resolution) maps as inputs. To achieve acceptable accuracies, it is important that the full variation in landscape types within the study area is well covered by the VHR imagery or similar input data. In Bavaria, which has a very
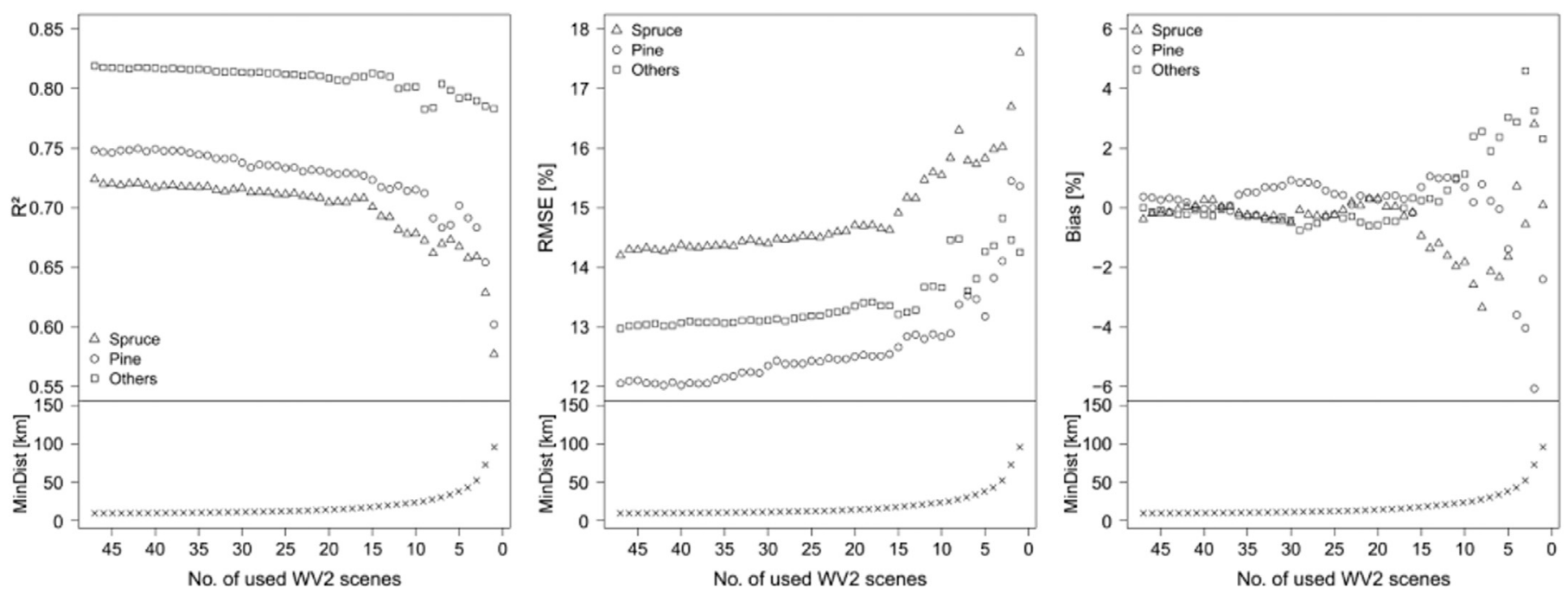

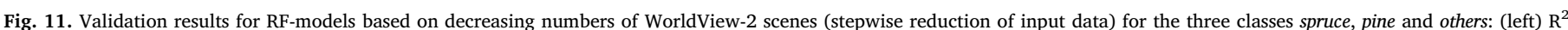

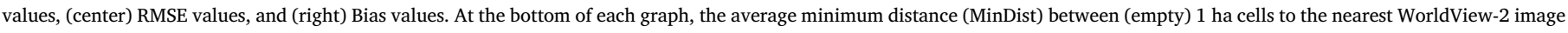
used is shown. 
heterogeneous landscape ranging from the Alps to lowlands, we found that the very high resolution reference data should cover roughly $1 \%$ of the total area in order to achieve 10-15\% accuracy (RMSE) for mapping fractional coverage of spruce and pine. For our data set, less comprehensive coverage significantly increased the modeling errors, as local variation in spectral signatures was no longer captured.

The approach presented here is likely transferable to many other remote sensing applications, and could potentially also work with other VHR data (e.g., orthophotos, UAV, aerial airborne hyperspectral data) combined with other decametric inputs such as Sentinel-2 instead of Landsat data.

\section{Acknowledgments}

The work has been partly supported by grants provided within the research project E52 TreeIdent, funded through the Bavarian State Ministry of Food, Agriculture and Forestry. This support is greatly appreciated. We would also like to thank the Bavarian State Forest Enterprise for providing field inventory data; Gerald Lindner, Gerhard Mocza, Wai-Tim Ng, Valentin Pesendorfer, Martin Siklar and Franz Suppan for supporting the WV2 classification; Matteo Mattiuzzi for assisting data preparation and modeling; and Anne Reichmuth and the DLR team for their help with WV2 data processing. The authors also gratefully acknowledge the efforts of four anonymous reviewers who offered valuable recommendations, and Laura Carlson for language editing.

\section{Appendix A. Supplementary material}

Supplementary material to this article can be found online at https://doi.org/10.1016/j.rse.2017.09.031.

\section{References}

AdV, 2015. Amtliches Topographisch-Kartographisches Informationssystem (ATKIS) [WWW Document]. Arbeitsgemeinschaft Vermess. Länder Bundesrepub. Dtschl URL. http://www.adv-online.de/AAA-Modell/ATKIS/, Accessed date: 7 January 2016.

Beck, P.S.A., Atzberger, C., Høgda, K.A., Johansen, B., Skidmore, A.K., 2006. Improved monitoring of vegetation dynamics at very high latitudes: a new method using MODIS NDVI. Remote Sens. Environ. 100, 321-334.

Bengtsson, R.J., 2014. matrixStats: Methods that Apply to Rows and Columns of a Matrix, R Package.

Breiman, L., 2001. Random forests. Mach. Learn. 45, 5-32. http://dx.doi.org/10.1023/ A: 1010933404324.

Brus, D.J., Hengeveld, G.M., Walvoort, D.J.J., Goedhart, P.W., Heidema, A.H., Nabuurs, G.J., Gunia, K., 2012. Statistical mapping of tree species over Europe. Eur. J. For. Res. 131, 145-157. http://dx.doi.org/10.1007/s10342-011-0513-5.

Carleer, A., Wolff, E., 2004. Exploitation of very high resolution satellite data for tree species identification. Photogramm. Eng. Remote. Sens. 70, 135-140.

Core Team, R., 2014. R: A Language and Environment for Statistical Computing. R Foundation for Statistical Computing, Vienna, Austria.

Donmez, C., Berberoglu, S., Erdogan, M.A., Tanriover, A.A., Cilek, A., 2015. Response of the regression tree model to high resolution remote sensing data for predicting percent tree cover in a Mediterranean ecosystem. Environ. Monit. Assess. 187, 1-12. http://dx.doi.org/10.1007/s10661-014-4151-5.

EEA, 2017a. Forests - Copernicus land monitoring service [WWW Document]. Copernic. Programme. URL. http://land.copernicus.eu/pan-european/high-resolution-layers/ forests, Accessed date: 8 February 2017.

EEA, 2017b. CORINE Land Cover - Copernicus Land Monitoring Service [WWW Document]. Copernic. Programme. URL. http://land.copernicus.eu/pan-european/ corine-land-cover, Accessed date: 8 February 2017.

Einzmann, K., Immitzer, M., Böck, S., Bauer, O., Schmitt, A., Atzberger, C., 2017. Windthrow detection in European forests with very high-resolution optical data. Forests 8, 21. http://dx.doi.org/10.3390/f8010021.

Fassnacht, F.E., Latifi, H., Stereńczak, K., Modzelewska, A., Lefsky, M., Waser, L.T., Straub, C., Ghosh, A., 2016. Review of studies on tree species classification from remotely sensed data. Remote Sens. Environ. 186, 64-87. http://dx.doi.org/10. 1016/j.rse.2016.08.013.

Fassnacht, F.E., Mangold, D., Schäfer, J., Immitzer, M., Kattenborn, T., Koch, B., Latifi, H., 2017. Estimating stand density, biomass and tree species from very high resolution stereo-imagery - towards an all-in-one sensor for forestry applications? Forestry 1-19. http://dx.doi.org/10.1093/forestry/cpx014.

Fries, R.S.D., Hansen, M., Townshend, J.R.G., Sohlberg, R., 1998. Global land cover classifications at $8 \mathrm{~km}$ spatial resolution: the use of training data derived from Landsat imagery in decision tree classifiers. Int. J. Remote Sens. 19, 3141-3168. http://dx.doi.org/10.1080/014311698214235.

Gómez, C., White, J.C., Wulder, M.A., 2016. Optical remotely sensed time series data for land cover classification: a review. ISPRS J. Photogramm. Remote Sens. 116, 55-72. http://dx.doi.org/10.1016/j.isprsjprs.2016.03.008.

Griffiths, P., Linden, S. van der, Kuemmerle, T., Hostert, P., 2013. A pixel-based landsat compositing algorithm for large area land cover mapping. IEEE J. Sel. Top. Appl. Earth Obs. Remote Sens. 6, 2088-2101. http://dx.doi.org/10.1109/JSTARS.2012. 2228167.

Gudex-Cross, D., Pontius, J., Adams, A., 2017. Enhanced forest cover mapping using spectral unmixing and object-based classification of multi-temporal Landsat imagery. Remote Sens. Environ. 196, 193-204. http://dx.doi.org/10.1016/j.rse.2017.05.006.

Guyon, I., Weston, J., Barnhill, S., Vapnik, V., 2002. Gene selection for cancer classification using support vector machines. Mach. Learn. 46, 389-422. http://dx.doi.org/ 10.1023/A:1012487302797.

Hansen, M.C., Defries, R.S., Townshend, J.R.G., Sohlberg, R., 2000. Global land cover classification at $1 \mathrm{~km}$ spatial resolution using a classification tree approach. Int. J. Remote Sens. 21, 1331-1364. http://dx.doi.org/10.1080/014311600210209.

Hansen, M.C., Potapov, P.V., Moore, R., Hancher, M., Turubanova, S.A., Tyukavina, A., Thau, D., Stehman, S.V., Goetz, S.J., Loveland, T.R., Kommareddy, A., Egorov, A., Chini, L., Justice, C.O., Townshend, J.R.G., 2013. High-resolution global maps of 21st-century forest cover change. Science 342, 850-853. http://dx.doi.org/10.1126/ science. 1244693.

Hastie, T., Tibshirani, R., Friedman, J., 2009. The elements of statistical learning: data mining, inference, and prediction, 2nd ed. Springer, New York, USA.

Hermosilla, T., Wulder, M.A., White, J.C., Coops, N.C., Hobart, G.W., 2015. An integrated Landsat time series protocol for change detection and generation of annual gap-free surface reflectance composites. Remote Sens. Environ. 158, 220-234. http://dx.doi. org $/ 10.1016 /$ j.rse.2014.11.005.

Hijmans, R.J., 2014. Raster: Geographic Data Analysis and Modeling, R Package.

Immitzer, M., Atzberger, C., Koukal, T., 2012. Tree species classification with Random Forest using very high spatial resolution 8-band WorldView-2 satellite data. Remote Sens. 4, 2661-2693. http://dx.doi.org/10.3390/rs4092661.

Immitzer, M., Toscani, P., Atzberger, C., 2014. The utility of wavelet-based texture measures to improve object-based classification of aerial images. South-East. Eur. J. Earth Obs. Geomat. 3, 79-84.

Immitzer, M., Einzmann, K., Böck, J., Mattiuzzi, M., Ng, W.-T., Wallner, A., Pinnel, N., Reichmuth, A., Frost, M., Müller, A., Seitz, R., Atzberger, C., 2015. Erstellung von Fichten- und Kiefernanteilskarten auf Basis von Satellitendaten für Bayern. In: Forstl. Forschungsberichte Münch, pp. 21-34.

Immitzer, M., Stepper, C., Böck, S., Straub, C., Atzberger, C., 2016a. Use of WorldView-2 stereo imagery and National Forest Inventory data for wall-to-wall mapping of growing stock. For. Ecol. Manag. 359, 232-246. http://dx.doi.org/10.1016/j.foreco. 2015.10.018.

Immitzer, M., Vuolo, F., Atzberger, C., 2016b. First experience with sentinel-2 data for crop and tree species classifications in central Europe. Remote Sens. 8, 1-27. http:// dx.doi.org/10.3390/rs8030166.

Iverson, L.R., Cook, E.A., Graham, R.L., 1989. A technique for extrapolating and validating forest cover across large regions. Calibrating AVHRR data with TM data. Int. J. Remote Sens. 10, 1805-1812.

JRC, 2015. Forest mapping [WWW Document]. URL. http://forest.jrc.ec.europa.eu/ activities/forest-mapping/, Accessed date: 7 July 2016.

JRC, 2017. Joint research centre data catalogue - European Commission [WWW Document]. FISE For. Inf. Syst. Eur. URL. https://data.jrc.ec.europa.eu/collection/ fise, Accessed date: 8 February 2017.

Ju, J., Roy, D.P., 2008. The availability of cloud-free Landsat ETM + data over the conterminous United States and globally. Remote Sens. Environ. 112, 1196-1211. http://dx.doi.org/10.1016/j.rse.2007.08.011.

Karlson, M., Ostwald, M., Reese, H., Bazié, H.R., Tankoano, B., 2016. Assessing the potential of multi-seasonal WorldView-2 imagery for mapping West African agroforestry tree species. Int. J. Appl. Earth Obs. Geoinf. 50, 80-88. http://dx.doi.org/10. 1016/j.jag.2016.03.004.

Kim, S.-R., Lee, W.-K., Kwak, D.-A., Biging, G.S., Gong, P., Lee, J.-H., Cho, H.-K., 2011. Forest cover classification by optimal segmentation of high resolution satellite imagery. Sensors 11, 1943-1958. http://dx.doi.org/10.3390/s110201943.

Kim, D.-H., Sexton, J.O., Noojipady, P., Huang, C., Anand, A., Channan, S., Feng, M., Townshend, J.R., 2014. Global, Landsat-based forest-cover change from 1990 to 2000. Remote Sens. Environ. 155, 178-193. http://dx.doi.org/10.1016/j.rse.2014. 08.017.

Klemmt, H.-J., Neubert, M., Mößnang, M., Hopf, C., 2014. Nachhaltig und naturnah: Wald und Forstwirtschaft in Bayern - Ergebnisse der dritten Bundeswaldinventur. Ba yerische Landesanstalt für Wald und Forstwirtschaft (LWF), Freising.

Kölling, C., Dietz, E., Falk, W., Mellert, K.-H., 2009a. Provisorische Klima-Risikokarten als Planungshilfen für den klimagerechten Waldumbau. In: LWF-Wissen. 63. pp. 31-39.

Kölling, C., Knoke, T., Schall, P., Ammer, C., 2009b. Überlegungen zum Risiko des Fichtenanbaus in Deutschland vor dem Hintergrund des Klimawandels. Forstarchiv $80,42-54$.

Krauß, T., d'Angelo, P., Schneider, M., Gstaiger, V., 2013. The Fully Automatic Optical Processing System CATENA at DLR. Int. Arch. Photogramm. Remote. Sens. Spat. Inf. Sci. XL-1/W1, 177-183. http://dx.doi.org/10.5194/isprsarchives-XL-1-W1-1772013.

Kuhn, M., Wing, J., Weston, S., Williams, A., Keefer, C., Engelhardt, A., Cooper, T., Mayer, Z., 2014. Caret: Classification and Regression Training, R Package.

Liaw, A., Wiener, M., 2002. Classification and regression by randomForest. R News 2, $18-22$.

Lindner, M., Maroschek, M., Netherer, S., Kremer, A., Barbati, A., Garcia-Gonzalo, J., Seidl, R., Delzon, S., Corona, P., Kolström, M., Lexer, M.J., Marchetti, M., 2010. 
Climate change impacts, adaptive capacity, and vulnerability of European forest ecosystems. For. Ecol. Manag. 259, 698-709. http://dx.doi.org/10.1016/j.foreco. 2009.09.023.

Lindner, M., Fitzgerald, J.B., Zimmermann, N.E., Reyer, C., Delzon, S., van der Maaten, E., Schelhaas, M.-J., Lasch, P., Eggers, J., van der Maaten-Theunissen, M., Suckow, F., Psomas, A., Poulter, B., Hanewinkel, M., 2014. Climate change and European forests: what do we know, what are the uncertainties, and what are the implications for forest management? J. Environ. Manag. 146, 69-83. http://dx.doi.org/10.1016/j.jenvman. 2014.07.030.

Mack, B., Leinenkugel, P., Kuenzer, C., Dech, S., 2017. A semi-automated approach for the generation of a new land use and land cover product for Germany based on Landsat time-series and Lucas in-situ data. Remote Sens. Lett. 8, 244-253. http://dx.doi.org/ 10.1080/2150704X.2016.1249299.

Metzler, J.W., Sader, S.A., 2005. Model development and comparison to predict softwood and hardwood per cent cover using high and medium spatial resolution imagery. Int. J. Remote Sens. 26, 3749-3761. http://dx.doi.org/10.1080/01431160500104152.

Mora, B., Wulder, M.A., White, J.C., 2010. Identifying Leading Species Using Tree Crown Metrics Derived from Very High Spatial Resolution Imagery in a Boreal Forest Environment.

Müller, R., Holzwarth, S., Habermeyer, M., Müller, A., 2005. Ortho image production within an automatic processing chain for hyperspectral airborne scanner ARES. In: Proceedings of the EARSeL Workshop 3D-Remote Sensing. Presented at the EARSeL Workshop 3D-Remote Sensing, Porto, Portugal.

Mutanga, O., Adam, E., Cho, M.A., 2012. High density biomass estimation for wetland vegetation using WorldView-2 imagery and random forest regression algorithm. Int. J. Appl. Earth Obs. Geoinf. 18, 399-406. http://dx.doi.org/10.1016/j.jag.2012.03. 012.

Omer, G., Mutanga, O., Abdel-Rahman, E.M., Adam, E., 2015. Performance of support vector machines and artificial neural network for mapping endangered tree species using WorldView-2 data in Dukuduku Forest, South Africa. IEEE J. Sel. Top. Appl. Earth Obs. Remote Sens. 1-16. http://dx.doi.org/10.1109/JSTARS.2015.2461136.

Pal, M., 2005. Random forest classifier for remote sensing classification. Int. J. Remote Sens. 26, 217-222. http://dx.doi.org/10.1080/01431160412331269698.

Pérez-Hoyos, A., García-Haro, F.J., San-Miguel-Ayanz, J., 2012. Conventional and fuzzy comparisons of large scale land cover products: application to CORINE, GLC2000, MODIS and GlobCover in Europe. ISPRS J. Photogramm. Remote Sens. 74, 185-201. http://dx.doi.org/10.1016/j.isprsjprs.2012.09.006.

Reinartz, P., 2010. The CATENA processing chain-multi-sensor pre-processing: orthorectification, atmospheric correction, future aspects. In: Proceedings of Geoland Forum_6. Presented at the Geoland Forum_6, Toulous.

Richter, R., Schläpfer, D., Müller, A., 2006. An automatic atmospheric correction algorithm for visible/NIR imagery. Int. J. Remote Sens. 27, 2077-2085. http://dx.doi. org/10.1080/01431160500486690.

Rouse, J., Haas, R., Schell, J., Deering, D., 1974. Monitoring vegetation systems in the Great Plains with ERTS. In: NASA Special Publication. Presented at the Third EERTS Symposium, pp. 309-317.

Schultz, B., Immitzer, M., Formaggio, A.R., Sanches, I.D.A., Luiz, A.J.B., Atzberger, C., 2015. Self-guided segmentation and classification of multi-temporal landsat 8 images for crop type mapping in Southeastern Brazil. Remote Sens. 7, 14482-14508. http:// dx.doi.org/10.3390/rs71114482.

Seidl, R., Vigl, F., Rössler, G., Neumann, M., Rammer, W., 2017. Assessing the resilience of Norway spruce forests through a model-based reanalysis of thinning trials. For. Ecol. Manag. Ecol. Mt. For. Ecosyst. Eur. 388, 3-12. http://dx.doi.org/10.1016/j foreco.2016.11.030.
Sexton, J.O., Song, X.-P., Feng, M., Noojipady, P., Anand, A., Huang, C., Kim, D.-H., Collins, K.M., Channan, S., DiMiceli, C., Townshend, J.R., 2013. Global, 30-m resolution continuous fields of tree cover: Landsat-based rescaling of MODIS vegetation continuous fields with lidar-based estimates of error. Int. J. Digital Earth 6, 427-448. http://dx.doi.org/10.1080/17538947.2013.786146.

Stepper, C., Straub, C., Immitzer, M., Pretzsch, H., 2017. Using canopy heights from digital aerial photogrammetry to enable spatial transfer of forest attribute models: a case study in central Europe. Scand. J. For. Res. 0, 1-48. http://dx.doi.org/10.1080/ 02827581.2016.1261935.

StMELF, 2013. Fitnessprogramm für Bayerns Wälder Klimamaßnahmen der Forstverwaltung - Zwischenbilanz und Ausblick. Bayerisches Staatsministerium für Ernährung, Landwirtschaft und Forsten, München.

Thompson, S.D., Nelson, T.A., White, J.C., Wulder, M.A., 2015. Mapping dominant tree species over large forested areas using landsat best-available-pixel image composites. Can. J. Remote. Sens. 41, 203-218. http://dx.doi.org/10.1080/07038992.2015. 1065708.

Toscani, P., Immitzer, M., Atzberger, C., 2013. Texturanalyse mittels diskreter Wavelet Transformation für die objektbasierte Klassifikation von Orthophotos. In: Photogramm. - Fernerkund. - Geoinformation 2, pp. 105-121. http://dx.doi.org/10. 1127/1432-8364/2013/0162.

Townshend, J.R., Masek, J.G., Huang, C., Vermote, E.F., Gao, F., Channan, S., Sexton, J.O., Feng, M., Narasimhan, R., Kim, D., Song, K., Song, D., Song, X.-P., Noojipady, P., Tan, B., Hansen, M.C., Li, M., Wolfe, R.E., 2012. Global characterization and monitoring of forest cover using Landsat data: opportunities and challenges. Int. J. Digital Earth 5, 373-397. http://dx.doi.org/10.1080/17538947.2012.713190.

Vuolo, F., 2016. Example Data: Smoothing and Gap-filling of High ResolutionMultispectral Time Series: Example of Landsat Data.

Vuolo, F., Ng, W.-T., Atzberger, C., 2017. Smoothing and gap-filling of high resolution multi-spectral time series: example of Landsat data. Int. J. Appl. Earth Obs. Geoinf. 57, 202-213. http://dx.doi.org/10.1016/j.jag.2016.12.012.

Walentowski, H., Gulder, H.-J., Kölling, C., Ewald, J., Türk, W., 2001. Die regionale natürliche Waldzusammensetzung Bayerns, LWF-Wissen. Bayer. Landesanst. für Wald u. Forstwirtschaft, Freising.

Waser, L.T., Ginzler, C., Kuechler, M., Baltsavias, E., Hurni, L., 2011. Semi-automatic classification of tree species in different forest ecosystems by spectral and geometric variables derived from Airborne Digital Sensor (ADS40) and RC30 data. Remote Sens. Environ. 115, 76-85. http://dx.doi.org/10.1016/j.rse.2010.08.006.

Waser, L.T., Küchler, M., Jütte, K., Stampfer, T., 2014. Evaluating the potential of WorldView-2 data to classify tree species and different levels of ash mortality. Remote Sens. 6, 4515-4545. http://dx.doi.org/10.3390/rs6054515.

White, J.C., Wulder, M.A., Hobart, G.W., Luther, J.E., Hermosilla, T., Griffiths, P., Coops, N.C., Hall, R.J., Hostert, P., Dyk, A., Guindon, L., 2014. Pixel-based image compositing for large-area dense time series applications and science. Can. J. Remote. Sens. 40, 192-212. http://dx.doi.org/10.1080/07038992.2014.945827.

White, J.C., Stepper, C., Tompalski, P., Coops, N.C., Wulder, M.A., 2015. Comparing ALS and image-based point cloud metrics and modelled forest inventory attributes in a complex coastal forest environment. Forests 6, 3704-3732. http://dx.doi.org/10. 3390/f6103704.

Zhu, Z., Evans, D.L., 1994. U.S. forest types and predicted percent forest cover from AVHRR data. Photogramm. Eng. Remote. Sens. 60, 525-531.

Zhu, Z., Woodcock, C.E., Holden, C., Yang, Z., 2015. Generating synthetic Landsat images based on all available Landsat data: predicting Landsat surface reflectance at any given time. Remote Sens. Environ. 162, 67-83. http://dx.doi.org/10.1016/j.rse. 2015.02.009. 